\title{
Kaum Muda dan Karier Profesional William Gunawan'
}

\section{K} arier merupakan satu dari tiga masalah besar yang harus diperhatikan dalam pelayanan kaum muda. Kinnaman mengatakan, tiga fenomena besar pada anak muda yang terhilang dari gereja dan Tuhan adalah (1) hubungan/relasi mendalam; (2) karier profesional; dan (3) hikmat. ${ }^{2}$ Area yang sering dilupakan dalam pelayanan kaum muda adalah karier profesional, perjumpaan antara iman dan panggilan yang sering terabaikan. ${ }^{3}$ Banyak anak muda Kristen terpanggil untuk melayani dalam bidang-bidang utama kehidupan seperti menjadi ilmuwan, dokter, pendidik, ahli psikologi, ahli hukum, ahli keuangan dan lain-lain. Tetapi kebanyakan dari mereka tidak mendapat panduan bagaimana mengaitkan antara visi misi hidup mereka secara profesional dengan iman mereka di dalam Kristus.

Tantangan semakin membesar manakala memperhatikan perkembangan karier di Indonesia saat ini. Gunawan, mengungkapkan pada dekade ini seseorang cenderung lebih cepat berpindah karier dari satu pekerjaan ke pekerjaan lain dan berganti tempat kerja dari satu perusahaan ke perusahaan lain. ${ }^{4}$ Bolles menambahkan, cara perekrutan karyawan termutakhir menggunakan cara dan metode yang sangat berbeda dengan masa lalu, yaitu dengan menitikberatkan pada penerapan teknologi, khususnya internet dan media sosial. ${ }^{5}$ Bukti konkret adalah penetrasi LinkedIn di Indonesia selama setahun lalu mencapai 4 juta pengguna dan mencatat kenaikan $40 \%{ }^{6}$

1. William Gunawan, S.Psi., M.Min., M.Si., dosen Konseling Karier di Fakultas Psikologi UKRIDA. Pembina Komisi Remaja di Gereja Kristen Indonesia (GKI) Perniagaan. Indonesia Country Director of Asia Pacific Career Development Association (APCDA). Sejak Februari 2016 melanjutkan studi Ph.D. dalam bidang Career Development di School of Applied Psychology, Griffith University, Australia.

2. David Kinnaman, You Lost Me: Why Young Christians Are Leaving Church, and Rethinking Faith (Grand Rapids: Baker Publishing Group, 2011).

3. William Gunawan, "Pengaruh Sumber-Sumber Efikasi Diri dan Efikasi Diri Pengambilan Keputusan Karier Terhadap Adaptabilitas Karier Remaja” (Tesis, Universitas Indonesia, Depok, 2013).

4. William Gunawan, "Adap bilitas Karier: Strategi Menghadapi AFTA dan Memanfaatkan Bonus Demografi," Jurnal NOETIC Psychology 4 No. 2 (Juli-Desember 2014): 113-120.

5. Richard N. Bolles, What Color is Your Parachute?: A Practical Manual for Job-Hunters and Career-Changers, ed. 41th (Berkeley, United States: Ten Speed Press, 2013).

6. Trisno Heriyanto, “LinkedIn Punya 4 Juta Pengguna di Indonesia,” http://www.cnnindonesia.com/teknologi/20150228162017185-35673/linkedin-punya-4-juta-pengguna-di-indonesia/ (diakses 20 Januari 2015). 


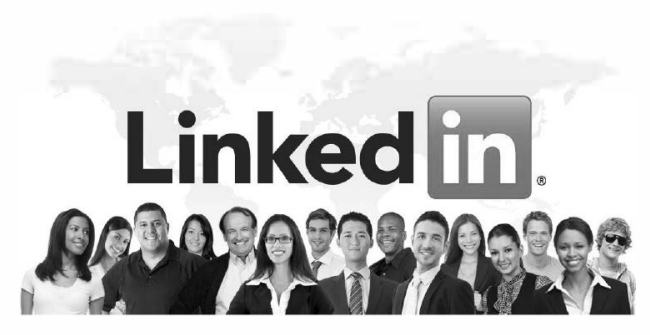

Karsandi mengatakan, LinkedIn umumnya digunakan oleh para head hunter perusahaan untuk mencari tahu informasi tentang kandidat yang ingin dicari, terutama untuk "membajak" karyawan. Sementara di sisi pengguna, LinkedIn digunakan sebagai portofolio untuk personal branding yang efektif. Perubahan metode perekrutan dan pencarian pekerjaan ini terjadi secara simultan, baik dalam skala nasional di negara masing-masing, juga secara regional antar kawasan, bahkan dalam skala multinasional di seluruh dunia.

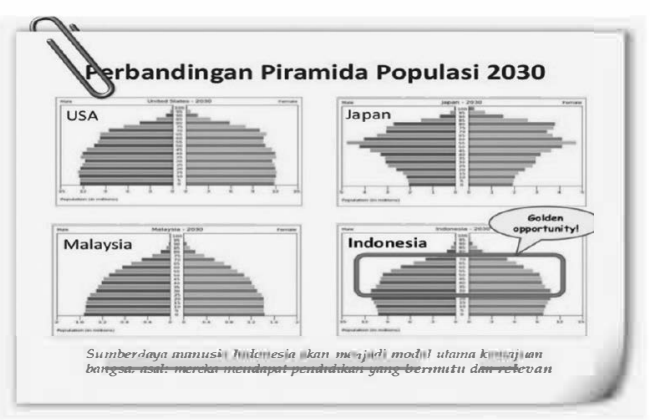

Secara regional, mulai Desember 2015, Indonesia dan negara-negara di Asia
Tenggara yang tergabung dalam Assosiation of South East Asian Nations (ASEAN) akan mulai memberlakukan suatu model perdagangan bebas yang disebut dengan Asean Free Trade Area (AFTA). AFTA merupakan kesepakatan di antara negaranegara ASEAN untuk membentuk kawasan perdagangan bebas, dengan tujuan utama meningkatkan daya saing ekonomi dan bisn is ASEAN di tengah dunia. ${ }^{7}$ Selain AFTA, Indonesia juga akan segera menghadapi bonus demografi. Bonus demografi merupakan istilah untuk menggambarkan kondisi jumlah penduduk usia kerja yang produktif (usia 15-64 tahun) yang melebihi jumlah penduduk berusia tidak produktif. Menteri Pendidikan dan Kebudayaan, Mohamad Nuh mengatakan, pada periode 2010 - 2035 Indonesia akan mendapatkan karunia potensi sumber daya manusia berupa populasi usia produktif terbesar sepanjang sejarah Indonesia. Nuh mengatakan bahwa potensi sumber daya manusia tersebut harus dikelola agar berkualitas dan benar-benar menjadi bonus demografi dan bukan bencana demografi. ${ }^{8}$ Prof. Sri Moertiningsih Adioetomo, guru besar ekonomi kependudukan di Universitas Indonesia, mengatakan bahwa penduduk mempunyai peranan penting dalam upaya peningkatan ekonomi. ${ }^{9}$ Perubahan struktur umur penduduk akibat transisi demografi jangka panjang berdampak pada peningkatan

7. Gunawan, “Adaptabilims Karier: Strategi Menghadapi AFTA dan Memanfaatkan Bonus Demografi," 113-120.

8. Mohamad Nuh, "The Republic of Indonesia, Minister of Youth dan Sports," Opening Stement of the Minister of Youth dan Sports at Round Table Meeting on the Strategic Approach for the Development of Indonesian Youth, Kompas.com, 10 September 2013.

9. Sri Moertiningsih Adioetomo, "Age-Structural Transitions and Their Implication: The Case of Indonesia Over Century, 19502050," dalam Age-Structural Transitions: Challenge for Development, ed. Ian Pool, Laura R. Wong, dan Éric Vilquin (Paris: Committee for International Cooperation in National Research in Demography, 2006), http://www.cicred.org/Eng/Publications/pdf/AgeStructuralBook.pdf (diakses 20 Januari 2015).

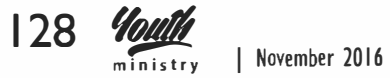




\section{Kurang dari $10 \%$ jemaat pemuda remaja yang hadir yang menyatakan bahwa topik karier penah dibahas di dalam acara di gereja. Hal ini merupakan kenyataan yang menyedihkan, karena pergumulan utama yang menjadi perhatian kaum muda justru tidak pernah diperhati- kan oleh gereja dan pelayanan kaum muda.}

jumlah tenaga kerja, penumpukan kekayaan yang lebih besar, dan tersedianya human capital yang jumlahnya lebih besar dibandingkan waktu-waktu sebelumnya.

Menghadapi diberlakukannya AFTA di tahun 2015 dan menyongsong bonus demografi pada tahun 2010-2035, maka generasi muda yang berada dalam usia produktif harus memiliki pemahaman yang baik terhadap kondisi ini dan mempersiapkan diri dan kualitasnya menghadapi dunia kerja. Adioetomo mengingatkan bahwa bonus demografi ini akan berdampak positif bila penduduk usia kerja produktif yang merupakan sumber potensi tenaga kerja berkualitas mampu memperlihatkan produktifitasnya dengan baik dan memiliki daya saing yang tinggi. ${ }^{10}$

Fakta-fakta ini merupakan kondisi riil yang siap tidak siap harus kita hadapi.
Ketidaksiapan, keacuhan dan pembiaran akan membawa kita jatuh semakin dalam dalam lubang kegagalan dan ketiadaan harapan. Namun kenyataannya, pembahasan dan perhatian terhadap perkembangan karier belum menjadi fokus utama dalam pelayanan pemuda remaja di Indonesia. Dalam diskusi yang mengemuka pada saat dilakukan Indonesia Youth Festival di Universitas Kristen Krida Wacana (UKRIDA), tahun 2014 yang lalu, didapatkan fakta bahwa hanya sedikit sekali Kom isi Pemuda dan Remaja yang hadir dalam pertemuan tersebut yang menyatakan bahwa mereka menaruh perhatian secara khusus terhadap topik karier. Lebih dalam lagi, kurang dari $10 \%$ jemaat pemuda remaja yang hadir yang menyatakan bahwa topik karier penah dibahas di dalam acara di gereja. Hal ini merupakan kenyataan yang menyedihkan, karena pergumulan utama yang menjadi perhatian kaum muda jus-

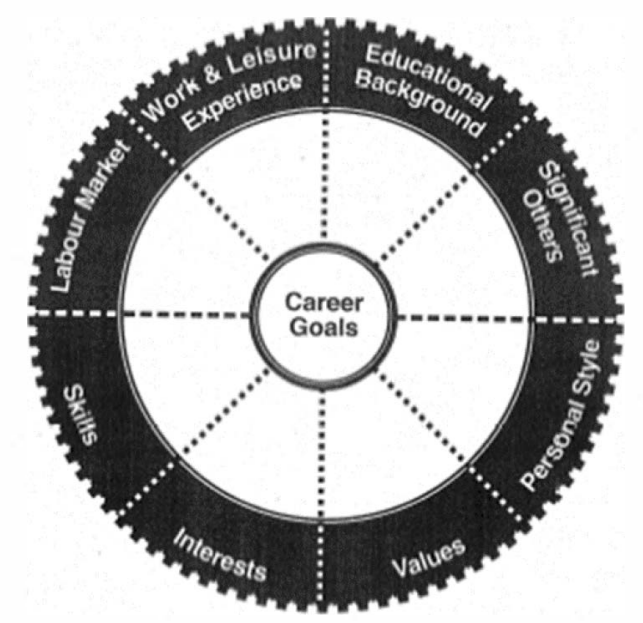

10. Adioetomo, "Age-Structural Transitions and Their Implication: The Case of Indonesia Over Century, 1950-2050." 
tru tidak pernah diperhatikan oleh gereja dan pelayanan kaum muda.

Tulisan ini disajikan untuk memberikan suatu wawasan bagi para pelayan kaum muda maupun kaum muda untuk memahami berbagai aspek dan ruang lingkup yang perlu diperhatikan dalam memikirkan karier profesional. Untuk memberikan suatu pengantar, penulis menggunakan suatu teori yang sederhana, jelas namun cukup komprehensif, yaitu teori roda karier (career wheel).

Teori Roda karier/career wheel merupakan teori karier yang dipopulerkan oleh Amundson. ${ }^{11}$ Roda merupakan temuan revolusioner sejak berabad-abad lampau yang berperan penting dalam transportasi. Sebuah roda terdiri dari beberapa bagian, yaitu sumbu/poros, dan jari-jari. Yang menjadi sumbu dalam teori ini adalah tujuan karier/career goals, yaitu tujuan yang ingin dicapai dalam berkarier. ${ }^{12}$ Jarijarinya berjumlah delapan, menyiratkan delapan aspek yang perlu diperhatikan dalam merencanakan karier. Delapan aspek dalam roda karier dibagi menjadi dua bagian, yaitu bagian bawah dan bagian atas. Bagian bawah tersusun atas empat aspek internal antara lain keterampilan, minat, nilai hidup dan tipe kepribadian, sementara bagian atas terdiri dari empat aspek lainnya yang bersifat eksternal. Kedelapan aspek ini merupakan bagian internal dan eksternal dari diri seseorang yang harus dipahami terlebih dulu dalam perencanaan karier. ${ }^{13}$ Mari kita melihat satu per satu dari delapan aspek ini: (1) Keterampilan-keterampilan; (2) Minatminat; (3) Nilai-nilai hidup; (4) Tipe kepribadian; (5) Orang-orang yang berperan dalam kehidupan; (6) Pembelajaran; (7) Pengalaman kerja dan pengalaman hidup, dan aspek terakhir (8) Peluang karier. ${ }^{14}$

\section{(1) Keterampilan-Keterampilan/ Skills ${ }^{15}$}

Tes bakat minat dapat membantu kita mengenali keterampilan-keterampilan yang kita miliki. Namun hasil tes saja tidak cukup untuk memberikan data guna pengambilan keputusan karier di masa depan. Bahkan ketika hasil tes digunakan untuk menentukan jurusan di bangku SMA, kesimpulan yang didapatkan dari hasil tes sering kali secara prematur membatasi pilihan karier di masa datang. Misalnya kesimpulan hasil tes menyarankan siswa untuk memilih jurusan IPS yang membatasi kemungkinan untuk me-

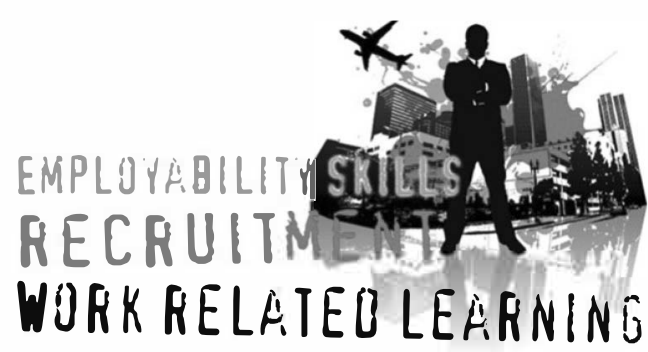

11. Norman E. Amundson, Active Engagement: The Being and Doing of Career Counselling, ed. 3rd (Richmond, BC: Ergon Communications, 2009).

12. Amundson, Active Engagement.

13. Roberta Neault, Career Strategies for a Lifetime of Success, ed. 3rd (Aldergrove, BC: Life Strategies 2012).

14. Amundson, Active Engagement.

15. Amundson, Active Engagement. 
masuki jurusan kedokteran atau psikologi di masa datang, atau sebaliknya siswa yang dianjurkan memilih jurusan IPA menjadikan siswa tersebut merasa gagal jika nantinya memilih jurusan bisnis atau desain.

Saat melayani siswa, kita dapat mengenali minat dan bakat mereka dengan menelusuri catatan sekolah mereka (rapor, hasil ujian, penghargaan, dlsb.) dan berdiskusi dengan mereka tentang kekuatan dan kelemahan mereka dan membahas bagaimana masukan yang mereka dapatkan berkaitan dengan hasil yang mereka capai. Jika melayani mahasiswa, kita dapat melakukan hal serupa berdasarkan rekaman capaian mereka dalam perkuliahan ditambah pengalaman magang mereka. Bagi kaum muda yang pernah bekerja atau berada di bangku terakhir kuliah, akan sangat informatif jika menelusuri employability skill mereka yang secara umum terbagi atas fundamental skills (komunikasi, penyelesaian masalah, mengelola informasi), management skills (tanggung jawab, adaptasi, perilaku positif) dan team work skills (bekerja sama, berpartisipasi). ${ }^{16}$ Selain itu, menganalisis adaptabilitas karier mereka, kesiapan kerja mereka, dan motivated

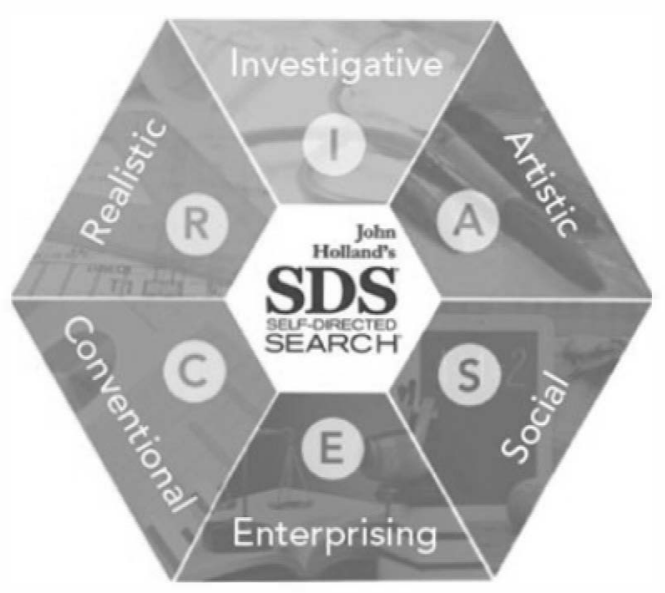

dalam tentang keterampilan kaum muda. ${ }^{17}$

\section{(2) Minat-Minat/Interests ${ }^{18}$}

Aspek lain yang agak mudah untuk dikenali dan digali adalah minat. Selain tes bakat, maka minat merupakan aspek lain yang mendapatkan perhatian khusus. Secara sederhana melakukan tes minat adalah upaya untuk membandingkan minat dalam diri dengan pilihan karier yang ada. Seseorang perlu memiliki pengetahuan tentang beragam pilihan karier agar mampu mengembangkan minat terhadap karier tersebut. Jika seorang individu belum memiliki pengetahuan tentang pilihan karier tersebut, maka seseorang

16. Frisdha Syaehfuddy dan William Gunawan, "Employability Skills Mahasiswa," Jurnal NOETIC Psychology (2016).

17. William Gunawan, "Success After School: Career Intervention Program for Senior High School Students in Indonesia" (makalah dipresentasikan pada Asia Pacific Career Development Association 1st Annual Conference, Seoul, South Korea, 2013) http://www.asiapacificcda.org/page-1581296\#Gunawan (diakses 20 Januari 2015); Sisca dan William Gunawan, “Gambaran Adaptabilitas Karier Remaja," Jurnal Fakultas Psikologi Universitas Islam Sultan Syarif Kasim Riau 11 No. 2 (Desember 2015 ): 111 119.; Angelika dan William Gunawan. Jurnal MindSet, Fakulas Psikologi Universi Pancasila, 2016; Riesca Monica dan William Gunawan, "Efikasi Diri Karier dan Adap bilitas Karier," Jurnal NOETIC Psychology (2016); Deliani dan William Gunawan, “Kesiapan Kerja Mahasiswa," Jurnal NOETIC Psychology (2016)

18. Amundson, Active Engagement. 
tidak mungkin mengembangkan minat terhadap karier itu.

Hasil penelitian mahasiswa UKRIDA Tjieputra dan Megalena menunjukkan bahwa, minat terbesar remaja dan pemuda di Jakarta terbagi dalam beberapa kelompok utama. ${ }^{19}$ Remaja wanita memiliki minat yang besar pada aktivitas dan jurusan perkuliahan ataupun lapangan pekerjaan di bidang sosial dan dan seni. Di bidang sosial misalnya dalam bidang psikologi, ilmu komunikasi, keguruan pendidikan maupun keperawatan. Sementara di bidang seni misalnya berkuliah dan bekerja dalam bidang desain produk, desain grafis, perhotelan, pariwisata maupun dalam musik. Remaja pria di Jakarta menunjukkan minat yang besar dalam bidang teknik dan kewirausahaan. Bidang teknik misalnya mempelajari dan bekerja dalam bidang teknik industri, arsitektur maupun sipil, sementara dalam bidang kewirausahaan misalnya menjadi entrepreneur, ekonomi keuangan, dan manajemen bisnis. Hasil ini signifikan dengan banyaknya bidang pekerjaan yang ada dan tersedia di masyarakat Indonesia saat ini, antara lain sebagai ahli ekonomi (bisnis, manajemen, akuntan), teknik, khususnya manufaktur dan bidang sosial (psikologi, guru) juga dalam bidang kesenian (seniman, artis).

Berikut ini beberapa pertimbangan yang harus diperhatikan dalam melaku- kan tes minat. Pertama, seseorang harus memiliki pengetahuan akan pilihan karier sebelum bisa mengembangkan minat dalam karier tersebut. Tanpa pengetahuan dan eksplorasi yang cukup mendalam tentang suatu pilihan karier, seseorang cenderung melakukan pilihan minat dengan cara terlalu prematur mengeliminasi berbagai pilihan karier yang tidak diketahuinya atau membuat pilihan minat karier secara dangkal berdasarkan masukan dari teman-teman atau iklan-iklan di TV dan media lainnya. ${ }^{20}$ Kedua, minat seseorang cenderung dinamis, sesuai dengan seberapa banyak dan seberapa dalam informasi baru mengenai minat yang didapatkannya. Minat yang disukai kaum muda di masa remajanya, mungkin akan berbeda pada masa remajanya, seiring dengan semakin bertambahnya informasi yang didapatkan. ${ }^{21}$ Ketiga, keberadaan alat tes minat di Indonesia yang merupakan tes minat yang diadaptasi dari Amerika di tahun 1970-1980, atau yang sedikit baru di tahun 2000-an seperti SDS (Self Directed Search). Alat tes ini disusun berdasarkan pilihan pekerjaan yang ada dan diminati di Amerika pada tahun-tahun disusunnya alat tes minat tersebut, bukan berdasarkan kondisi terkini dan kurang sesuai dengan konteks Indonesia. Misalnya saja, dalam alat tes minat yang tersedia saat ini, kita tidak akan mendapatkan pilihan minat karier sebagai motivator,

19. Josephine Tjieputra, “Minat Mahasiswa UKRIDA," (Skripsi S.Psi., Universi uKRIDA, 2013); Melia Megalena, "Gambaran Minat Remaja di Jakarta," (Skripsi S.Psi., Universitas UKRIDA, 2015).

20. Neault, "Beyond Test and Tell"

21. Neault, "Beyond Test and Tell."

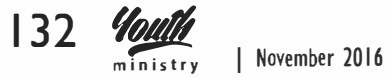


financial planner, actuary ataupun stand up comedian. ${ }^{22}$ Maka dari itu, memilih karier berdasarkan minat semata bagaikan membangun rumah di atas pasir yang pondasinya rapuh dan dapat runtuh setiap saat. Mengenali minat hendaknya dilakukan secara bersama-sama dengan aspek lainnya dalam roda karier.

\section{(3) Nilai-Nilai Hidup/Life Values ${ }^{23}$}

Dalam pengalaman bertahun-tahun sebagai konselor karier, Neault mengatakan bahwa konflik utama yang paling sering muncul dalam diri kaum muda yang gagal dalam karier atau mengalami ketidakpuasan karier bukanlah karena keterampilan atau minat, melainkan dalam nilai hidup. ${ }^{24}$ Konflik nilai yang muncul bisa terjadi di dalam dirinya sendiri, atau konflik antara nilai individu dengan nilai organisasi atau nilai profesi, atau konflik nilai antara individu dengan individu lain dalam organisas i. Karena itu selain memahami keterampilan dan minat, nilai kehidupan dan nilai kerja perlu ditelusuri dan dipahami. Nilai kehidupan berkaitan dengan nilai-nilai utama yang penting dan bernilai bagi hidup kita, misalkan prestasi, kebajikan, keindahan, kebebasan, keadilan, religius, kekayaan, kesederhanaan dan lainnya. Seseorang yang memiliki nilai utama keadilan dalam hidupnya, akan menikmati pilihan karier yang menghargai adanya keadilan dan kebenaran dalam pekerjaan yang dilakukannya. Nilai bekerja berkaitan dengan tujuan untuk bekerja, pencapaian yang diharapkan melalui pekerjaan, dan etos bekerja yang dimiliki. Seorang karyawan yang memiliki etos kerja yang lemah dan bekerja hanya sekadar mencari uang pasti tidak akan bertahan lama pada waktu bekerja di organisasi yang mengutamakan kerja keras, kecepatan, ketepatan dan menghargai inovasi.

Ada 14 nilai-nilaiutama dalam kehidupan yang penting dan relevan untuk diketahui, antara lain prestasi, rasa ingin diterima, kepedulian ter hadap lingkungan, kepedulian terhadap orang lain, kreativitas, kesejah teraan keuangan, kesehatan, kerendahan hati, kebebasan, kemandirian, privasi, analisis objektif, tanggung jawab dan spiritualitas. ${ }^{25}$ Berdasarkan daftar nilai-nilai tersebut, kita dapat melakukan refleksi pribadi dengan menanyakan kepada diri sendiri beberapa pertanyaan berikut: Apa yang mendorong saya untuk bekerja? Apa yang menjadi target dalam membangun karier? Hal-hal apa yang saya pentingkan dalam bekerja? Etos kerja seperti apa yang saya miliki?

\section{(4) Tipe Kepribadian/Personal Style ${ }^{26}$}

Tuhan menciptakan setiap individu sebagai pribadi yang unik dan memiliki

22. Neault, "Beyond Test and Tell."

23. Amundson, Active Engagement.

24. Roberta Neault, "Beyond Test and Tell," Jurnal NOETIC Psychology 4 No. 2 (Juli-Desember 2014): 113-120.

25. Arivika Akanda Putri dan William Gunawan, "Uji Validi dan Realibi sife Value Inventory," Jurnal NOETIC PSychology 4 No. 2 (Juli-Desember 2014): 185-187.

26. Amundson, Active Engagement. 


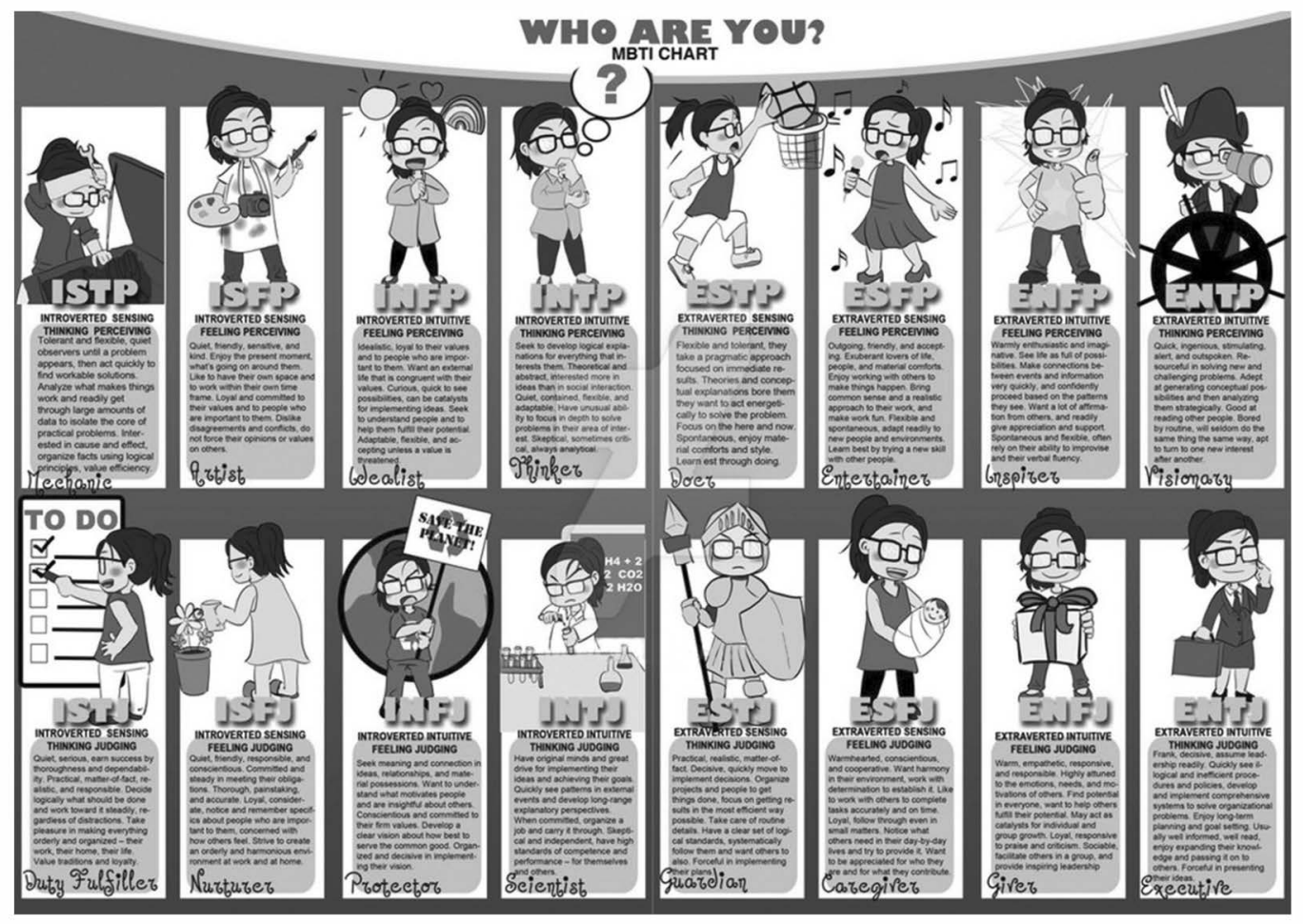

kepribadian berbeda satu dengan yang lain. Teori kepribadian yang cukup sederhana, populer dan mudah dipahami adalah Myers-Briggs Type Indicator (MBTI). ${ }^{27}$ Teori kepribadian ini mengidentifikasi bagaimana cara orang berelasi, berpikir, dan berinteraksi dengan orang lain. Misalnya saja dalam cara seseorang memperoleh energi dari dalam diri (introvert) atau dari sumber luar diri seperti bersama dengan orang lain (extrovert). Cara seseorang memperoleh energi ini akan berpengaruh pada lingkungan kerja, apakah seseorang lebih tepat untuk bekerja sebagai costumer service di front office yang sibuk dan banyak berinterkasi dengan orang atau lebih tepat bekerja di dalam ruangan kantor tertutup yang memberi- kan kesempatan untuk refleksi pribadi. Namun demikian, tes kepribadian lebih menggambarkan kecenderungan pribadi seseorang daripada menggambarkan kekuatan dan kelemahan karakteristik seseorang secara spesifik. Informasi ini baik dan dapat digunakan untuk refleksi pribadi, namun demikian tidak cukup dan tidak tepat untuk digunakan sebagai satusatunya alat diagnosa seleksi karyawan. Kepribadian hanyalah aspek penunjang yang harus diperhatikan, tetapi bukan yang utama. Kaum muda yang tertarik mengenali diri lebih dalam melalui tes kepribadian MBTI dapat menelusuri internet dan menemukan berbagai situs yang memberikan layanan tes gratis.

27. https://www.myersbriggs.org/my-mbti-personality-type/mbti-basics/home.htm?bhcp=1

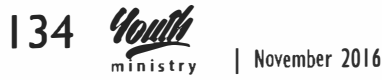


(5) Orang-Orang yang Berperan dalam Kehidupan/Significant Others ${ }^{28}$

Dari pengalaman pribadi memberikan ceramah dan konseling karier selama ini di berbagai kota di Indonesia, penulis menemukan temuan penting tentang keterlibatan orang-orang terdekat dalam pengambilan keputusan karier. Orang tua di Indonesia memegang peranan penting dalam perencanaan karier kaum muda, terutama remaja, bahkan beberapa pemuda. Peran orang tua malah bisa dikatakan terlalu berlebihan dalam memengaruhi pengambilan keputusan karier remaja dan pemuda. Dalam salah satu perbincangan dengan orang tua siswa di kegiatan pengabdian masyarakat Sukses Setelah Sekolah, seorang ayah yang frustasi mendatangi saya agar "mengatur" hasil psikotes dan konseling sesuai keinginannya, yaitu supaya sang anak belajar ekonomi bisnis, padahal hasil tes psikologi dan konseling menyarankan anaknya untuk mengambil jurusan yang sama sekali berbeda. Han mengungkapkan dengan gamblang kebiasaan orang tua di Singapura yang menjadikan anaknya sebagai investasi untuk meraup miliaran dolar sebagai modal di hari tua orang tua. ${ }^{29}$ Neault menambahkan fenomena yang serupa terjadi juga di Canada. Menurutnya, dalam masa perubahan lingkungan pekerjaan yang berkembang sangat cepat, orang tua tidak diperlengkapi dengan keteram- pilan bimbingan karier yang baik dan mutakhir. ${ }^{30}$ Pengetahuan orang tua tentang bidang pekerjaan yang spesifik hanya mencakup 10-40 dari ribuan pilihan pekerjaan yang ada saat ini. Belum lagi jika bicara soal pengembangan karier anak, perencanaan jalur karier ataupun pemahaman tentang teori perkembangan karier. Akhirnya, remaja pemuda sering kali dipaksa orang tua untuk membuat pilihan karier yang terlalu cepat sebelum mereka melakukan pengenalan diri dan eksplorasi karier yang cukup mendalam.

Namun demikian, pengaruh orang tua terhadap pengambilan keputusan karier remaja pemuda ini merupakan modal sumber daya yang bisa bermanfaat jika dikelola dan diatur dengan baik. Penelitian yang dilakukan oleh Siane dan Gunawan mengungkapkan bahwa semakin tinggi dukungan orang tua maka semakin jelas pula pengambilan keputusan karier pada remaja. ${ }^{31}$ Orang tua hendaknya berperan sebagai pembimbing, pendukung yang ikut belajar bersama dengan remaja pemuda untuk mengembangkan pengetahuan kariernya. Orang tua memiliki kesempatan unik dan bersifatjangka panjang untuk membantu merencanakan karier remaja dan pemuda. Kesempatan ini harus dikembangkan dengan melakukan dialog dan diskusi terarah dengan remaja pemuda untuk mengenali kekuatan yang ada pada diri remaja menyangkut

28. Amundson, Active Engagement.

29. Kwok Kwang Han, Million Dollar Mission: Exploring Career Success with Your Teen (Singapore: Candid Creation Publishing, 2015).

30. Roberta Neault, "Beyond Test and Tell," Jurnal NOETIC Psychology 4 No. 2 (Juli-Desember 2014).

31. Siane dan William Gunawan, "Dukungan Orang Tua Terhadap Pengambilan Keputusan Karier Remaja," Jurnal NOETIC Psychology (2016). 
empat aspek pengenalan diri di atas agar remaja mendapat dukungan untuk bereksplorasi dan mengenal dirinya secara menyeluruh dan aman. Selain itu orang tua juga berperan dalam menyediakan kesempatan bagi anak remaja dan pemuda untuk melakukan eksplorasi pilihan karier, pengalaman kerja, pengalaman hidup yang luas dan pengenalan berbagai bidang karier yang ada di dalam masyarakat.

Angelika dan Gunawan mengungkapkan bahwa selain orang tua, dukungan sosial bagi remaja pemuda bisa berasal dari guru, teman dan orang-orang berpengaruh lainnya di sekitar kehidupan remaja. ${ }^{32}$ Berdasarkan pengalaman pribadi penulis, peran dari mentor, kakak rohani, pembimbing kelompok kecil, pembina remaja pemuda, penatua pendamping, pelatih paduan suara, pelatih gitar, pelatih drama bahkan pelatih futsal yang memiliki keteladanan dan relasi yang mendalam dengan remaja dan pemuda akan memberikan pengaruh yang positif dan signifikan dalam perencanaan karier remaja pemuda. Para pelayan kaum muda harus menyediakan waktu berkualitas untuk membicarakan dengan mendalam pergumulan karier remaja pemuda agar kebutuhan mereka dapat dipenuhi dengan cara yang tepat. Sama halnya dengan para orang tua yang peduli pada perkembangan karier, pelayan kaun muda juga perlu memperlengkapi diri dengan teori karier mutakhir dan pengetahuan mendalam tentang perencanaan karier.

\section{(6) Pembelajaran/Learning 33}

Pengalaman pendidikan formal yang diperoleh di sekolah akan memengaruhi perencanaan karier di masa depan. Calon dokter hanya bisa dihasilkan oleh jurusan IPA di SMA, dan para Akuntan banyak dihasilkan dari lulusan SMK Akuntansi. Namun demikian, pengalaman belajar secara informal juga memberikan banyak pengaruh dalam karier seseorang di masa depan. ${ }^{34}$ Pengalaman belajar formal di sekolah dapat diperdalam dengan menghubungkan pembelajaran di kelas dengan pilihan karier dan pengalaman karier ke depan. ${ }^{35}$ Misalnya saja dengan memberikan tugas-tugas proyek spesifik melalui studi kasus, pembuatan profil karier, penyusunan profil pekerjaan, mendatangkan ahli di bidang tertentu sebagai pembicara tamu, mengadakan kunjungan karyawisata, ataupun kunjungan ke berbagai perusahaan dan tempat publik seperti bandara, kantor polisi, kantor pemerintah dan lainnya untuk mempelajari berbagai jenis pekerjaan yang ada dan tersedia.

Perkembangan karier seseorang merupakan suatu proses dinamis yang berkembang seiring dengan perkembangan individu. Kedisiplinan dan semangat

\footnotetext{
32. Angelika dan William Gunawan. Jurnal MindSet, Fakultas Psikologi Universitas Pancasila, 2016.

33. Amundson, Active Engagement.

34. Neault, "Beyond Test and Tell"

35. Roberta Neault, "Beyond Test and Tell."
}

\section{Youtflf | November 2016}


belajar untuk memahami perkembangan karier terkini akan membuat remaja pemuda memiliki wawasan karier dan adaptabilitas karier yang bermanfaat untuk bertahan dalam persaingan global saat ini. ${ }^{36}$ Bagi remaja pemuda yang memiliki akses internet, melakukan penelusuran pekerjaan dan karier merupakan suatu aktivitas yang perlu dilakukan dengan serius dan intensif untuk memahami perkembangan tren karier terbaru. Demikian juga mengikuti berbagai diskusi terkait bidang karier tertentu melalui media online seperti LinkedIn akan sangat bermanfaat. Jika ada kesempatan tersedia, bergabung dengan kelompok diskusi atau komunitas yang memiliki karier yang sama akan sangat strategis.

\section{(7) Pengalaman Kerja dan Pengalaman Hidup/Work and Leisure Experiences ${ }^{37}$}

Aspek berikutnya dari roda karier menekankan pentingnya perencanaan karier yang dikaitkan dengan konteks pengalaman kerja dan pengalaman hidup seseorang. Karier seseorang merupakan bagian dari kehidupan yang tidak dapat dipisahkan dengan kehidupan sepanjang hayat seseorang. Pilihan pekerjan yang diambil saat ini selalu berkaitan dengan pengalaman masa lalu yang menyusun kepingan-kepingan puzzle kehidupan.

Salah satu konsep sederhana untuk memahami bagian ini adalah dengan mengajak remaja pemuda untuk merefleksikan transferable skills yang sudah mereka terapkan dalam berbagai pengalaman hidup. ${ }^{38}$ Transferable skills adalah serangkaian keahlian yang kita miliki dan kita gunakan di masa lalu dalam menyelesaikan tugas-tugas maupun pekerjaan yang kita lakukan yang akan bermanfaat dalam membangun karier di masa depan. Misalnya saja, dalam pengalaman sebagai konselor remaja, penulis melatih keahlian konseling, komunikasi, dan mendengarkan. Kemudian dalam pengalaman selanjutnya sebagai guru BK, penulis menambahkan skill konseling menjadi tingkat mahir, komunikasi dasar menjadi lanjutan, keahlian mendengarkan menjadi mendengarkan aktif, dan menambahkan keahlian tadi dengan keahlian mengajar, menulis dan merancang materi pembelajaran. Selanjutnya sebagai team marketing kampus, penulis mengembangkan keahlian dasar tadi dengan keahlian marketing, analisis strategis dan komunikasi persuasif. Dalam tahapan selanjutnya sebagai dosen, penulis mengembangkan lagi keahlian mengajar menjadi mengajar aktif, komunikasi kreatif, menulis jurnal dan mengembangkan bahan ajar, keahlian analisis ditingkatkan menjadi keahlian meneliti. Sederet keahlian ini dapat dikenali, diklasifikasikan dan dikelompokkan sehingga penulis memiliki keahlian yang terus dikembangkan sebagai bahan dasar

36. Gunawan, "Adaptabilitas Karier: Strategi Menghadapi AFTA dan Memanfaatkan Bonus Demografi," 113-120.

37. Amundson, Active Engagement.

38. Richard N. Bolles, What Color is Your Parachute?: A Practical Manual for Job-Hunters and Career-Changers, ed 41th (Berkeley, United Stes: Ten Speed Press, 2013). 
penyusunan portofolio pribadi (CV), riwayat hidup dan menjadi keahlian dasar untuk pengembangan diri dalam meraih karier di masa depan. Merefleksikan transferable skill secara berkala merupakan salah satu refleksi tambahan yang bisa kita lakukan pada saat melakukan evaluasi dan perencanaan berkala di akhir tahun ataupun saat kita berulang tahun.

\section{(8) Peluang Karier/ Career opportunities ${ }^{39}$}

Aspek terakhir dari roda karier berperan sebagai pengingat bahwa pilihan karier yang baik bukan sekadar berdasarkan pengenalan diri yang baik, tetapi juga realita perkembangan dunia kerja. Aspek terakhir ini memerlukan upaya lebih untuk mengenali dan mengantisipasi peluang karier ke depan yang berkaitan dengan profesi yang kita lakukan. Mengenali peluang karier dapat dilakukan secara sederhana dengan melihat daftar lowongan pekerjaan yang tersedia di berbagai media, atau membaca tulisan para analis dan konselor karier mengenai tren perkembangan karier terkini di dunia.

\section{Penutup dan Langkah Praktis bagi In- dividu dan Pelayan Kaum Muda}

Kaum muda dan remaja dapat menggunakan roda karier untuk menjadi cek list dalam mengenali aspek mana yang kurang kita kenali dalam diri kita dan memerlukan penelusuran lebih lanjut. Kebutuhan setiap individu akan sangat berbeda antara seorang dengan yang lain sesuai dengan pengalaman hidup masing-masing. Pengalaman hidup akan memperkaya kita dan membawa kita makin dekat pada tujuan hidup kita, seperti yang dikatakan Rick Warren, "We are products of our past, but we don't have to be prisoners of it." 40

Peyanan kaum muda dapat membahas tema-tema seputar karier dalam kegiatan pemuda remaja sesuai pergumulan pemuda remaja di komunitas masingmasing. Remaja SMP maupun SMA tentu akan memerlukan psikotes yang akan membantu mereka mengenali skill, minat, kepribadian dan nilai mereka. Pengalaman penulis memberikan layanan pengabdian masyarakat Sukses Setelah Sekolah yang menerapkan model psikotes, ceramah dan konseling terbukti efektif dalam meningkatkan pemahaman dan pengambilan keputusan karier remaja. ${ }^{41}$

Kaum muda dan remaja juga dapat membentuk kelompok diskusi, membangun komunitas berdasarkan pengembangan karier. Pengalaman penulis di GKI Perniagaan misalnya, komisi remaja dan pemuda secara berkala membahas topiktopik karier dalam suasana santai dan menghadirkan terciptanya dialog yang

39. Amundson, Active Engagement.

40. Rick Warren, The Purpose Driven Life: What on Earth am I Here for? (USA: Zondervan Publishing Company, 2007).

41. Daely dan William Gunawan, "Perbedaan Pengambilan Keputusan Karier Pada Remaja SMA Setelah dan Sebelum Mengikuti Program Intervensi Karier Sukses Setelah Sekolah” (makalah dipresen sikan pada Prosiding Konferensi Nasional II Psikologi Kesehatan, Universitas YARSI, Jakar , 21-22 Juni 2014).

\section{Youlff | November 2016}




\section{Perencanaan karier adalah proses jangka panjang} sepanjang rentang kehidupan. Tidak ada jalan singkat untuk membangun karier kita. Sama halnya seperti pertumbuhan rohani, perkembangan karier membutuhkan totalitas dan keteguhan hati.

melibatkan paramentor dan pembimbing yang lebih senior untuk memperkenalkan berbagai pekerjaan yang tersedia. Warren menantang kita membuat kelompok kecil yang memiliki kedalaman dan keaslian: "If you are a member of a small group or class, I urge you to make a group covenant that includes the nine characteristics of biblical fellowship: We will share our true feelings (authenticity), forgive each other (mercy), speak the truth in love (honesty), admit our weaknesses (humility), respect our differences (courtesy), not gossip (confidentiality), and make group a priority (frequency)." 42

Perencanaan karier adalah proses jangka panjang sepanjang rentang kehidupan. Tidak ada jalan singkat untuk membangun karier kita. Sama halnya seperti pertumbuhan rohani, perkembangan karier membutuhkan totalitas dan keteguhan hati. Upaya keras dan cerdas ini dalam upaya menjawab pertanyaan terbesar kehidupan, "Untuk apa aku di dunia ini?" Selamat mencari jawaban.

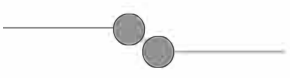

\section{Daftar Pustaka}

Adioetomo, Sri Moertiningsih. "Age-Structural Transitions and Their Implication: The Case of Indonesia Over Century, 1950-2050." Dalam Age-Structural Transitions: Challenge for Development, ed. Ian Pool, Laura R. Wong, dan Éric Vilquin (Paris: Committee for International Cooperation in National Research in Demography, 2006), http://www.cicred.org/Eng/Publications/pdf/AgeStructural-Book.pdf (diakses 20 Januari 2015).

Amundson, Norman E. Active Engagement: The Being and Doing of Career Counselling, ed. 3rd. Richmond. BC: Ergon Communications, 2009. 
Angelika dan William Gunawan. Jurnal MindSet. Fakultas Psikologi Universitas Pancasila, 2016.

Bolles, Richard N. What Color is Your Parachute?: A Practical Manual for Job-Hunters and Career-Changers, ed. 41th. Berkeley, United States: Ten Speed Press, 2013.

Daely dan William Gunawan. "Perbedaan Pengambilan Keputusan Karier Pada Remaja SMA Setelah dan Sebelum Mengikuti Program Intervensi Karier Sukses Setelah Sekolah." Makalah dipresentasikan pada Prosiding Konferensi Nasional II Psikologi Kesehatan, Universitas YARSI, Jakarta, 21-22 Juni 2014.

Deliani dan William Gunawan. "Kesiapan Kerja Mahasiswa." Jurnal NOETIC Psychology (2016).

Gunawan, William. "Adaptabilitas Karier: Strategi Menghadapi AFTA dan Memanfaatkan Bonus Demografi." Jurnal NOETIC Psychology 4 No. 2 (Juli-Desember 2014): 113120.

Gunawan, William. "Memahami Budaya Kaum Muda." Jurnal Youth Ministry 1 No. 2 (November 2013).

Gunawan, William. "Pengaruh Sumber-Sumber Efikasi Diri dan Efikasi Diri Pengambilan Keputusan Karier Terhadap Adaptabilitas Karier Remaja." Tesis, Universitas Indonesia, Depok, 2013.

Gunawan, William. "Success After School: Career Intervention Program for Senior High School Studen in Indonesia". Makalah dipresentasikan pada Asia Pacific Career Development Association 1st Annual Conference, Seoul, South Korea, 2013. Http://www.asiapacificcda.org/page-1581296\#Gunawan (diakses 20 Januari 2015).

Han, Kwok Kwang. Million Dollar Mission: Exploring Career Success with Your Teen. Singapore: Candid Creation Publishing, 2015.

Heriyanto, Trisno. "LinkedIn Punya 4 Juta Pengguna di Indonesia." http://www. cnnindonesia.com/teknologi/20150228162017-185-35673/linkedin-punya-4-jutapengguna-di-indonesia/ (diakses 20 Januari 2015).

Karsandi, Rusdi. "4 Fakta Pengguna Linkedin di Indonesia." https://www.linkedin.com /pulse/4-fakta-pengguna-linkedin-di-indonesia-rusdi-karsandi (diakses 20 Januari 2015).

\section{Ministry | November 2016}


Kinnaman, David You Lost Me: Why Young Christians Are Leaving Church, and Rethinking Faith. Grand Rapids: Baker Publishing Group, 2011.

Megalena, Melia. “Gambaran Minat Remaja di Jakarta.” Skripsi S.Psi., Universitas UKRIDA, 2015.

Monica, Riesca dan William Gunawan. "Efikasi Diri Karier dan Adaptabilitas Karier." Jurnal NOETIC Psychology (2016).

Neault, Roberta. "Beyond Test and Tell." Jurnal NOETIC Psychology 4 No. 2 (JuliDesember 2014): 113-120.

Neault, Roberta. Career Strategies for a Lifetime of Success, ed. 3rd. Aldergrove, BC: Life Strategies 2012.

Nuh, Mohamad. "The Republic of Indonesia, Minister of Youth dan Sports." Opening Statement of the Minister of Youth dan Sports at Round Table Meeting on the Strategic Approach for the Development of Indonesian Youth. Kompas.com, 10 September 2013.

Putri, Arivika Akanda dan William Gunawan. "Uji Validitas dan Realibitas Life Value Inventory." Jurnal NOETIC Psychology 4 No. 2 (Juli-Desember 2014): 185-187.

Siane dan William Gunawan. "Dukungan Orang Tua terhadap Pengambilan Keputusan Karier Remaja.” Jurnal NOETIC Psychology (2016).

Sisca dan William Gunawan. "Gambaran Adaptabilitas Karier Remaja." Jurnal Fakultas Psikologi Universitas Islam Sultan Syarif Kasim Riau 11 No. 2 (Desember 2015): 111-119.

Syaehfuddy, Frisdha dan William Gunawan. "Employability Skills Mahasiswa." Jurnal NOETIC Psychology (2016).

Tjieputra, Josephine. "Minat Mahasiswa UKRIDA.” Skripsi S.Psi., Universitas UKRIDA, 2013.

Warren, Rick. The Purpose Driven Life: What on Earth am I Here for? USA: Zondervan Publishing Company, 2007. 